\title{
Hydrogen Atom Abstraction by a Mononuclear Ferric Hydroxide Complex: Insights into the Reactivity of Lipoxygenase
}

\section{Supporting Information}

Christian R. Goldsmith, T. Daniel P. Stack*

Contribution from the Department of Chemistry, Stanford University, CA 94305

Contents:

Page S2. Metachloroperbenzoic acid (MCPBA) oxidation of $\left[\mathrm{Fe}^{\mathrm{II}}(\mathbf{P Y 5})(\mathrm{MeCN})\right]^{2+}$ to a mixture of $\left[\mathrm{Fe}^{\mathrm{III}}(\mathbf{P Y 5})(\mathrm{OH})\right]^{2+}$ and $\left[\mathrm{Fe}^{\mathrm{IV}}(\text { PY5 })(\mathrm{O})\right]^{2+}$.

Page S3. Comparative EPR spectra of $\left[\mathrm{Fe}^{\mathrm{III}}(\mathbf{P Y 5})(\mathrm{OH})\right]^{2+}$ and $\left[\mathrm{Fe}^{\mathrm{III}}(\mathbf{P Y 5})(\mathrm{OMe})\right]^{2+}$.

Page S4. Sample titration used to measure $\mathrm{pK}_{a}$ of $\left[\mathrm{Fe}(\mathbf{P Y 5})\left(\mathrm{H}_{2} \mathrm{O}\right)\right]^{2+}$.

Page S5. Cyclic Voltammetry of $\left[\mathrm{Fe}^{\mathrm{III}}(\mathbf{P Y 5})(\mathrm{OH})\right]^{2+}$ in $\mathrm{MeCN}$.

Page S6. IR spectrum of $\left[\mathrm{Fe}^{\mathrm{III}}(\mathbf{P Y 5})(\mathrm{OH})\right]^{2+}$ as a Nujols mull.

Page S7. Plot of $\log \left(k_{2 \text { corr }}\right)$ versus Substrate $\mathrm{p} K_{\mathrm{a}}$ for hydrocarbon reactivity of $\left[\mathrm{Fe}^{\mathrm{III}}(\mathbf{P Y 5})(\mathrm{OH})\right]^{2+}$.

Page S8. Eyring Plot of the Reduction of $\left[\mathrm{Fe}^{\mathrm{III}}(\mathbf{P Y 5})(\mathrm{OH})\right]^{2+}$ to $\left[\mathrm{Fe}^{\mathrm{II}}(\mathbf{P Y 5})(\mathrm{MeCN})\right]^{2+}$ in 9,10-Dihydroanthracene Solution.

Page S9. EPR spectra of $\left[\mathrm{Fe}^{\mathrm{III}}(\mathbf{P Y 5})(\mathrm{OH})\right]^{2+}$ before and after addition of 2,4,6-tri-t-butyl phenol.

*To whom correspondence should be addressed:

T.D.P.S. at Department of Chemistry, Stanford University, CA 94305, USA; Tel: (650) 725-8736; Fax: (650) 725-0259; email: stack@ stanford.edu 


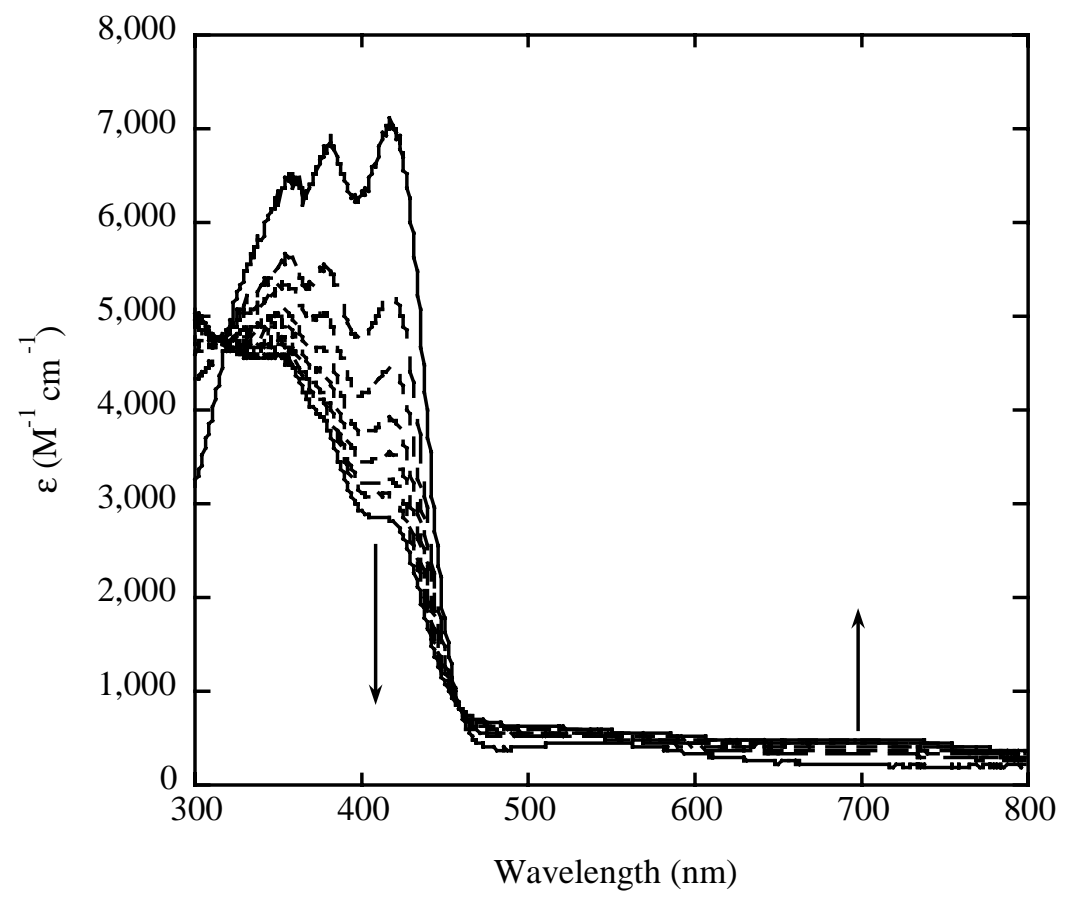

Figure S1. MCPBA oxidation of a $0.22 \mathrm{mM}$ solution of $[\mathrm{Fe}(\mathbf{P Y 5})(\mathrm{MeCN})]^{2+}$ to a mixture of $[\mathrm{Fe}(\mathbf{P Y 5})(\mathrm{OH})]^{2+}$ and $[\mathrm{Fe}(\mathbf{P Y 5})(\mathrm{O})]^{2+}(710 \mathrm{~nm}$ feature $)$ at $233 \mathrm{~K}$ in $\mathrm{MeCN}$. Scans are 15 min apart. Arrows indicate spectral changes upon oxidation. 


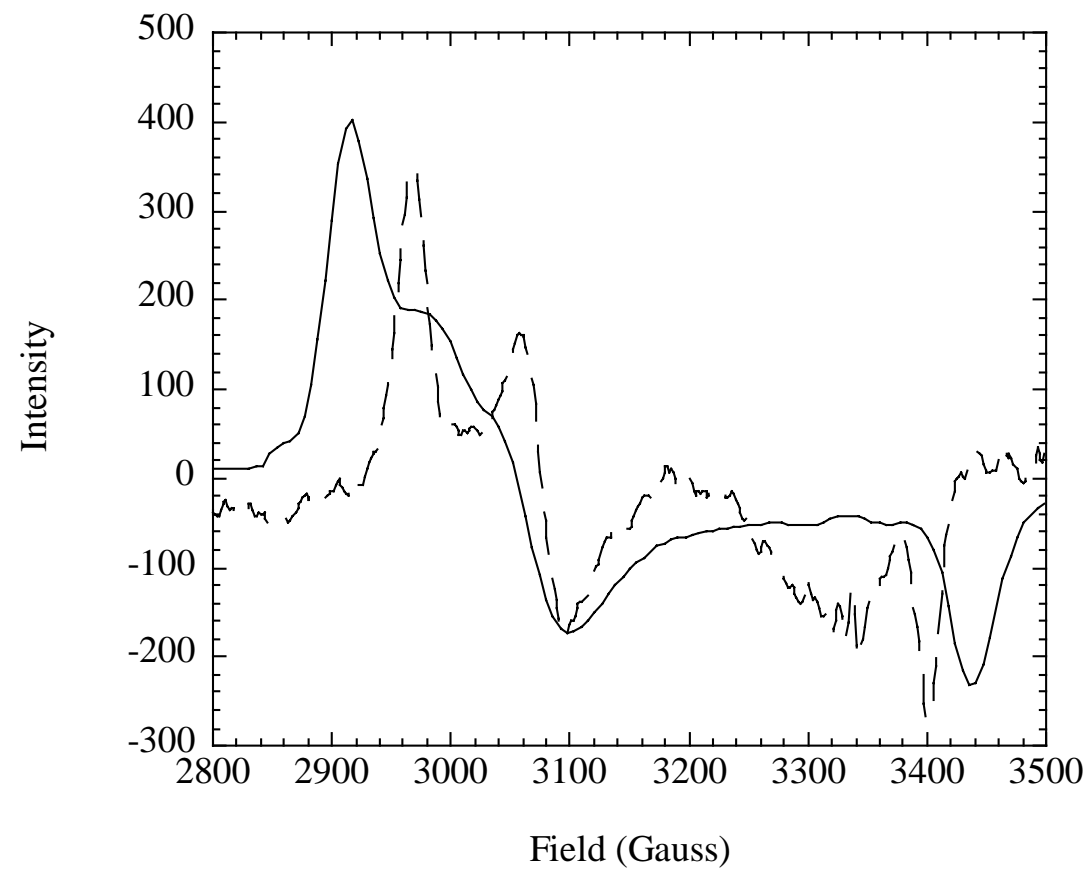

Figure S2. Comparative X-band EPR spectra of a $10 \mathrm{mM}$ sample of $\left[\mathrm{Fe}^{\mathrm{III}}(\mathbf{P Y} \mathbf{5})(\mathrm{OH})\right]^{2+}$ (solid line) and a $1 \mathrm{mM}$ sample of $\left[\mathrm{Fe}{ }^{\mathrm{III}}(\mathbf{P Y 5})(\mathrm{OMe})\right]^{2+}$ (dashed line) in $\mathrm{MeCN}$ at $77 \mathrm{~K}$. The intensities have been normalized to each other. 


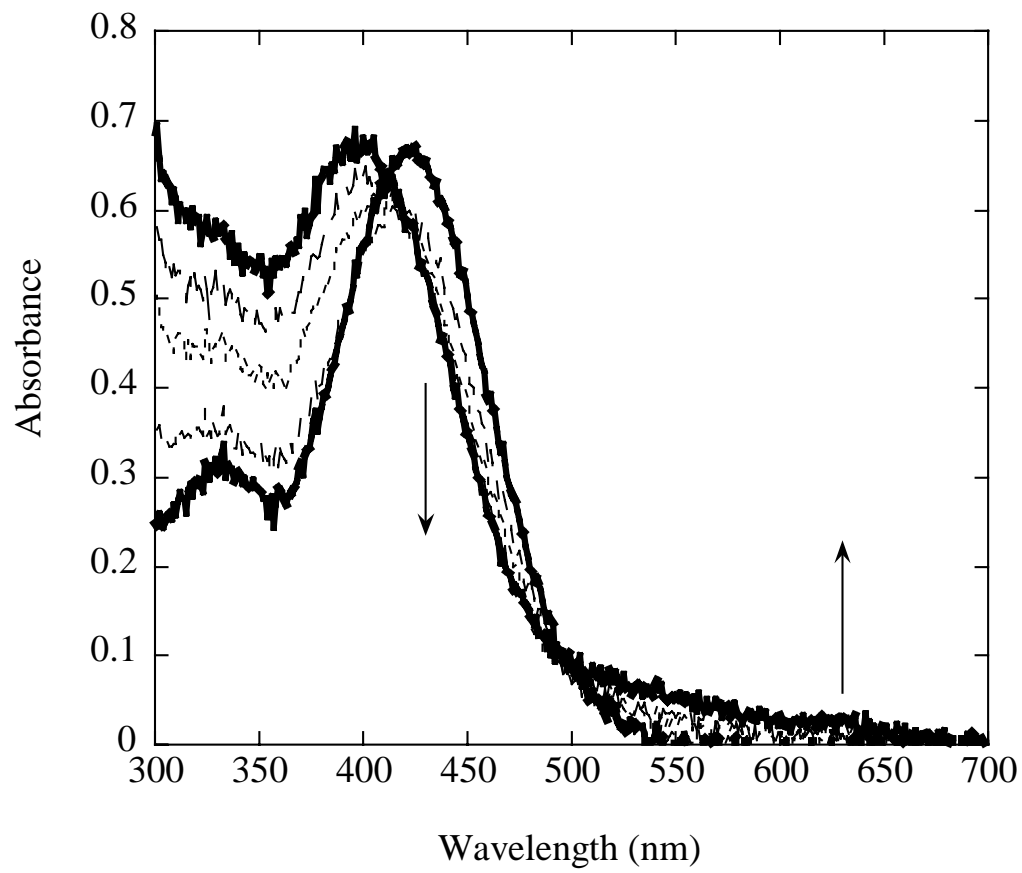

Figure S3. Titration of a $0.33 \mathrm{mM}$ bromocresol green solution in DMSO with a $9.2 \mathrm{mM}$ solution of $\left[\mathrm{Fe}(\mathbf{P Y 5})\left(\mathrm{H}_{2} \mathrm{O}\right)\right]\left(\mathrm{ClO}_{4}\right)_{2}$ in DMSO. Arrows indicate growth of protonated bromocresol green species. The end point spectrum corresponds to 39 equiv of $\mathrm{Fe}^{\mathrm{II}} \mathbf{L H}_{2} \mathrm{O}$ added ( $95 \%$ conversion). Spectra are taken at $298 \mathrm{~K}$ with a $1 \mathrm{~mm}$ pathlength. 


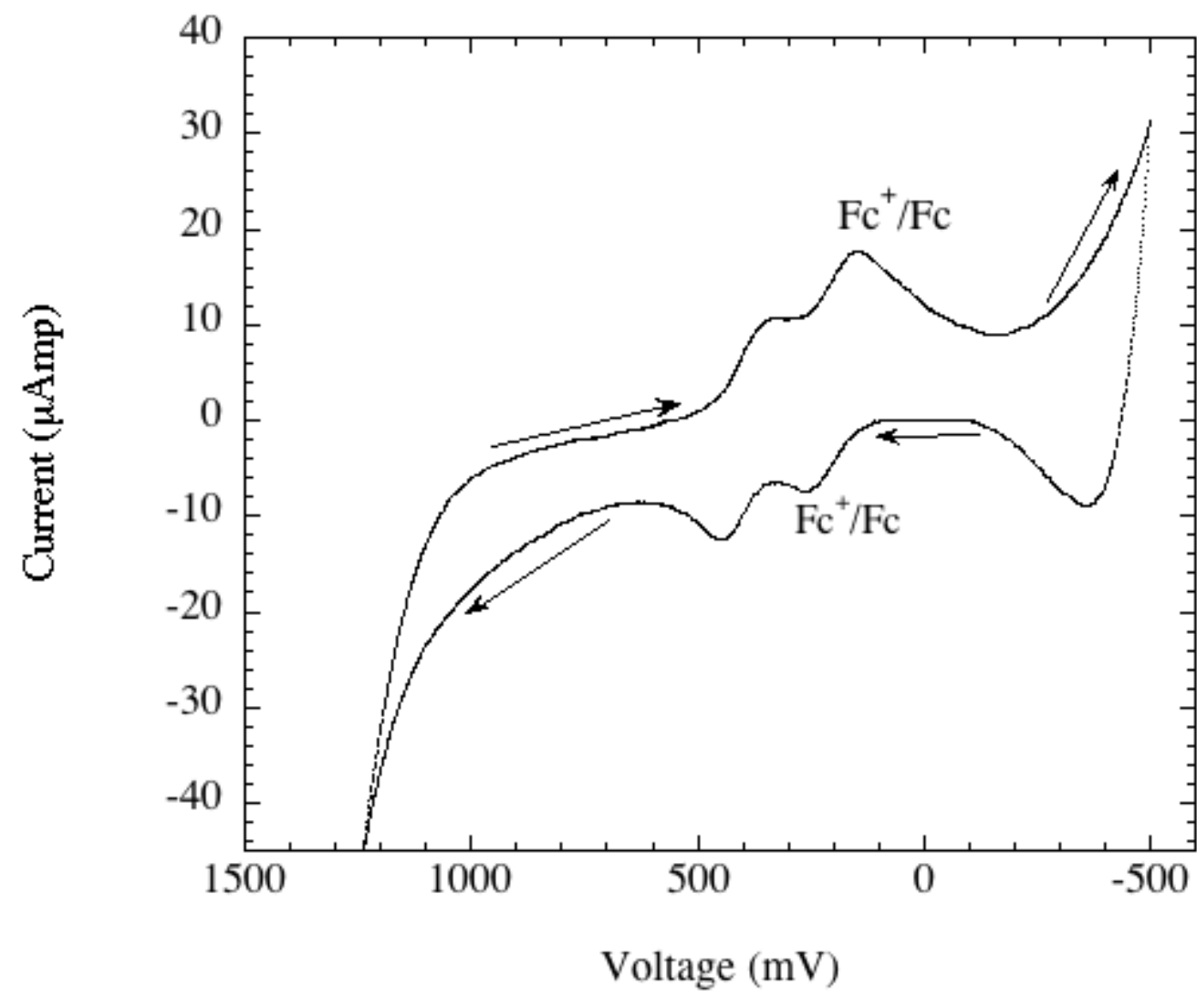

Figure S4.

Cyclic voltammetry of $\left[\mathrm{Fe}^{\mathrm{III}}(\mathbf{P Y 5})(\mathrm{OH})\right]^{2+}$ in $0.10 \mathrm{M}$ tetrabutylammonium perchlorate solution in DMSO. The arrows indicate the direction of the scan. The peaks at $440 \mathrm{mV}$ (anodic current) and $330 \mathrm{mV}$ (cathodic current) are due to the added ferrocene reference. 


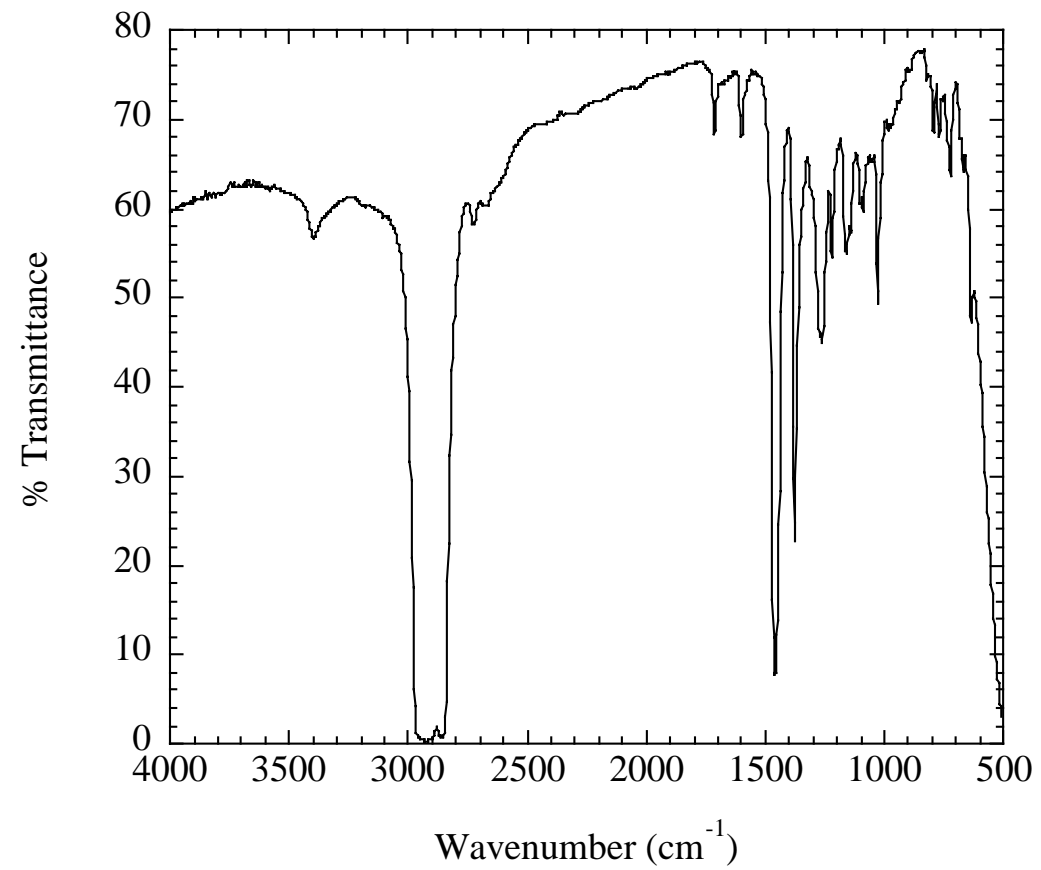

Figure S5. Infrared spectrum of $\left[\mathrm{Fe}^{\mathrm{III}}(\mathbf{P Y 5})(\mathrm{OH})\right]^{2+}$ as a Nujols mull. The peak at 3398 $\mathrm{cm}^{-1}$ is assigned as the $\mathrm{O}-\mathrm{H}$ stretch of the exogenous hydroxide. 


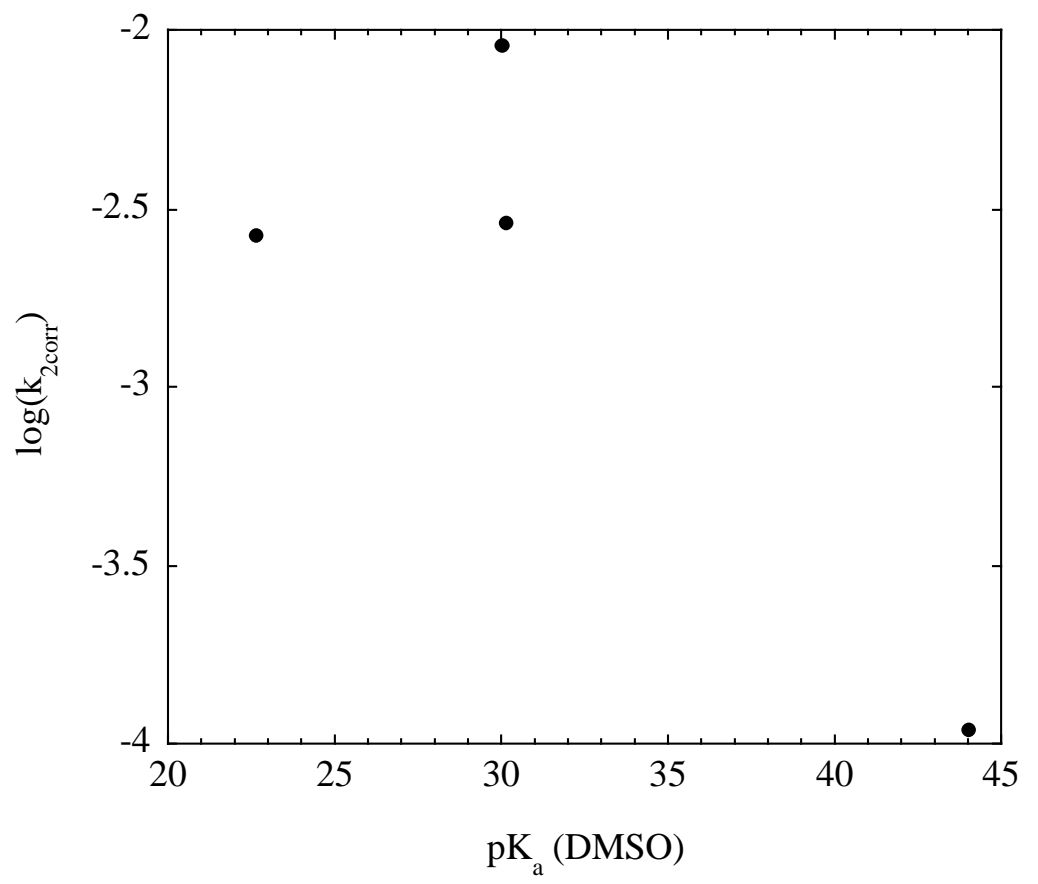

Figure S6. Plot of the $\log$ of the corrected rate constants $k_{2 \text { corr }}$ against substrate $\mathrm{p} K_{\mathrm{a}}$ (DMSO). The following substrates are represented on the plot ( $\mathrm{p} K_{\mathrm{a}}$ in parentheses): fluorene (22.6); xanthene (30.0); 9,10-dihydroanthracene (30.1); and ethylbenzene (44, Ref 18). All $\mathrm{p} K_{\mathrm{a}}$ values are from Ref 16 except where noted. Kinetic data are measured at $323 \mathrm{~K}$. 


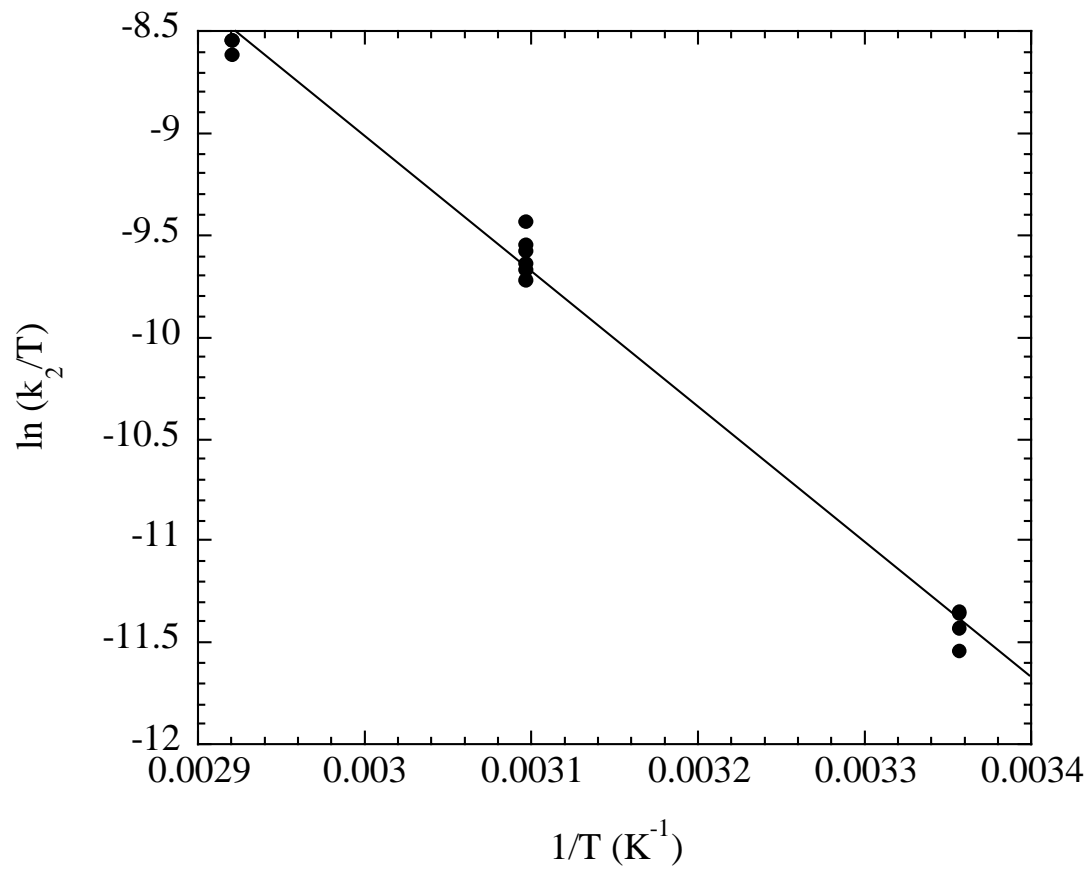

Figure S7. Eyring plot for the reduction of $0.7-1.5 \mathrm{mM}[\mathrm{Fe} I \mathrm{II}(\mathbf{P Y 5})(\mathrm{OH})]^{2+}$ by excess (>40 equiv) 9,10-dihydroanthracene (298-343 K) in anaerobic MeCN. 


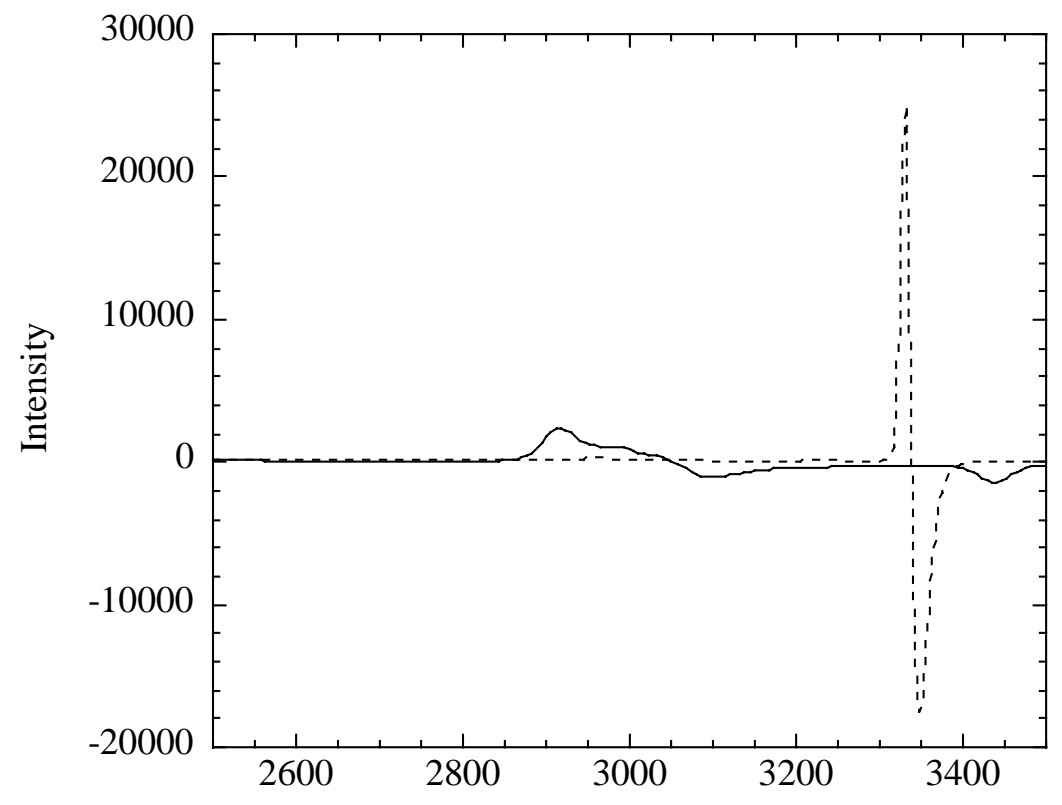

Field (Gauss)

Figure S8. EPR spectra of $\left[\mathrm{Fe}^{\mathrm{III}}(\mathbf{P Y 5})(\mathrm{OH})\right]^{2+}$ before (solid line) and after (dashed line) addition of 10 equiv of 2,4,6-tri-t-butylphenol (TTBP). The reaction is performed in $\mathrm{MeCN}$ at $298 \mathrm{~K}$ while the spectra are taken at $77 \mathrm{~K}$. Integration of the signals indicates that the concentration of the TTBP radical is $\sim 30 \%$ that of the original solution of $\left[\mathrm{Fe}{ }^{\mathrm{III}}(\mathbf{P Y} 5)(\mathrm{OH})\right]^{2+}$. 